\title{
Promoting self-regulated learning in higher education
}

\author{
Hermy Llacuna \\ h.1lacuna@,westernsydney.edu.au \\ Glenn Mason \\ g.mason@westernsydney.edu.au \\ University of Western Sydney \\ Keywords: self-regulated learning, higher education
}

\section{Abstract}

The importance of self-regulated learning is a heavily discussed topic in higher education. Existing literature indicates that self-regulated learning practices and strategies are relevant and important factors in student learning outcomes within blended and online contexts (Broadbent \& Poon, 2015). According to literature, the self-regulated learner is aware of their strengths and weaknesses. They set goals, monitor their progress through self-reflection and the constant evaluation of their learning approaches, which enables them to adapt their engagement in academic-related tasks (Hawe, Lightfoot \& Dixon, 2019). These are key principles of selfregulated learning, which aims to position learners as active agents in the learning process (Winne \& Perry, 2000).

Studies have found that students arrive at universities without the skills or practices required for self-regulated learning (Balapumi, von Konsky, Aitken, \& McMeekin, 2016). This is a crucial time for students, as they develop new ways of thinking, learning and communicating. Practices and strategies should be introduced to students as they begin their journey into tertiary studies, to ensure they are equipped with the necessary skills that are key to academic success (Lear \& Li \& Prentice, 2016). To develop students as independent, selfregulating learners has become a valued and desired outcome of higher education institutions, and as such they should offer opportunities to develop these skills as they progress though their studies (Hawe et al., 2019).

Therefore, to help and support students in the development and enhancement of their self-regulated learning skills, the Learn2Learn module, was developed by the Technology-Enabled-Learning (TEL) Team at Western Sydney University, and piloted to students in Autumn session, 2021. The key features and functionalities of the Learn2Learn module include, goal setting and study planning tools, lessons and content pieces informed by literature on self-regulated learning, and the ability for instructors to take a specific lesson and embed it in-line with their instructional materials within the LMS. Since its launch, there has been a consistent growth in usage. In Autumn 2021, there was a total of 427 users and 681 sessions have been initiated. Students are spending an average of approximately 8 minutes per session. In Spring 2021, there was a total of new 321 users, with 536 sessions, and an average of approximately 8 minutes per session.

More recently, three focus group sessions were conducted, consisting of 4 to 6 students. Students' experiences with the module confirmed its value in helping their self-regulated learning practices, including, setting goals, self-reflection, planning and time management. There was also a considerable number of responses from the students that have indicated that the module could benefit the first-year transition into university.

This presentation will cover the evidence and research that informed the content and design of the module We will provide some insight into the preliminary findings from quantitative and qualitative data analysis and discuss the development process of the module, including an overview of the learner experience (LX) design principles used to guide the design of the module, to help promote student engagement.

\section{References}

Balapumi, R., von Konsky, B. R., Aitken, A., \& McMeekin, D. A. (2016). Factors Influencing University Students' Self-regulation of Learning: An Exploratory Study. In Proceedings of the Australasian Computer 


\section{SoTEL Symposium 16-18 February 2022}

Science Week Multiconference (pp. 51-59). New York, NY, USA: ACM.

http://doi.org/10.1145/2843043.2843067

Broadbent, J., \& Poon, W. (2015). Self-regulated learning strategies \& academic achievement in online higher education learning environments: A systematic review. The Internet and Higher Education, 27, 1-13. https://doi.org/10.1016/j.iheduc.2015.04.007

Hawe, E., Lightfoot, U., \& Dixon, H. (2019). First-year students working with exemplars: promoting selfefficacy, self-monitoring and self-regulation. Journal of Further and Higher Education, 43(1), 30-44. https://doi.org/10.1080/0309877X.2017.1349894

Lear, E., Li, L., \& Prentice, S. (2016). Developing academic literacy through self-regulated online learning. Student Success, 7(1), 13-23.

Winne, P. H., \& Perry, N. (2000). Chapter 16-Measuring Self-Regulated Learning. In Handbook of SelfRegulation-(pp. 531-566). Retrieved from:

https://www .researchgate.net/publication/232472158 Measuring Self-Regulated Learning 